Utah State University

DigitalCommons@USU

$1-1-1978$

\title{
Measurements of Electron Density Structure in Striated Barium Clouds
}

K. D. Baker

Utah State University

J. C. Ulwick

Follow this and additional works at: https://digitalcommons.usu.edu/sdl_pubs

\section{Recommended Citation}

Baker, K. D. and Ulwick, J. C., "Measurements of Electron Density Structure in Striated Barium Clouds" (1978). Space Dynamics Lab Publications. Paper 4.

https://digitalcommons.usu.edu/sdl_pubs/4

This Article is brought to you for free and open access by the Space Dynamics Lab at DigitalCommons@USU. It has been accepted for inclusion in Space Dynamics Lab Publications by an authorized administrator of DigitalCommons@USU. For more information, please contact digitalcommons@usu.edu.

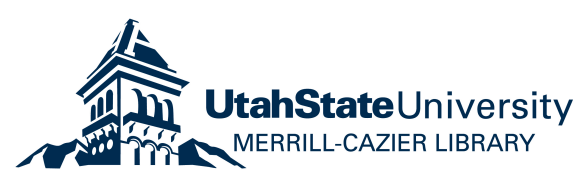



Geophysical Research Letters 5 (8): 723-26. doi:10.1029/GL005i008p00723.

\title{
MEASUREMENTS OF ELECTRON DENSITY STRUCTURE IN STRIATED BARIUM CLOUDS
}

\author{
K.D. Baker
}

Utah State University, Logan, Utah 84322

and

J.C. U1wick

Air Force Geophysics Laboratory, Hanscom Air Force Base, Massachusetts 01731

\begin{abstract}
Results are presented of the first measurements of detailed structure of electron density within striated vapor releases in the ionospheric F-region. Six rocket probes penetrated ion clouds in three separate barium release events (two in each case) and showed considerable enhancement in F-region electron density over the normal background ionization. In four traversals the electron density exceeded $10 \mathrm{~cm}^{-3}$ with the maximum of $5 \times 10^{6} \mathrm{~cm}^{-3}$ observed in one case. Two showed dramatic structure in the electron density profiles associated with the passage through striated portions of the cloud. These structures had spatial extent as measured by the rocket.probe normal to the terrestrial magnetic fleld of hundreds of meters with the density changing factors in the range from 2 to 10 as the probe passed into and out of the structures. The change of density on some of the features had particularly fast drop off corresponding to less than 20 meters travel normal to the magnetic field. The spectral power distribution of the irregularity amplitudes versus wavenumber scale size could be roughly described as a power law with a spectral index of from -2 to -3 within the striated regions. These results are in good agreement with predictions of the $\bar{E} \times \bar{B}$ gradient drift instability mechanism as depicted by the simulation studies of Scannapieco, et a1. [1976] in the late time nonlinear reglme.
\end{abstract}

\section{Introduction}

This brief note reports the results of measurements of electron density structure within the ion clouds associated with the release of barium vapor in the sunlit lower F-region. These barium releases and the measurements reported here were part of the Defense Nuclear Agency (DNA) sponsored program denoted as the STRESS (Satellite Transmission Effects Simulations) program. This field program, which included rockets, instrumented aircraft and ground-based observations, was carried out in February-March 1977 from the Eglin Gulf Test Center. The primary objective of the program was definition and characterization of the effects on radio wave propagation through the striated regions of the barium clouds and correlation of these effects with other observations of these regions. The striated Ion cloud regions were created by $48-\mathrm{kg}$ barium cannisters which were carried by rocket vehicles to about $185 \mathrm{~km}$ where the barium vapor was released into the sunlit atmosphere. After the barium releases,

Copyright 1978 by the American Geophysical Union. radar tracking and optical tracking (where possible) of the resulting cloud provided inputs for computer prediction of launch azimuth and elevation for a given launch time for additional rockets to intercept and penetrate the ionized portion of the barium cloud. These six additional rockets carried instruments for in situ measurement of fine-scale electron density structure, two each into three separate barium releases.

The use of barium vapor releases as a technique to study F-region electric fields and other atmospheric parameters has been utilized for a number of years [Haerendel and Lust, 1968; Haerendel and Lust, 1970; Davis and Wallis, 1972]. In this connection the general development of the ion cloud, including the formation of striations, has been widely observed and documented optically [Haerende1 et al., 1967; Rosenberg, 1971; Davis et al., 1974] and explained theoretically in terms of plasma instabilities [LInson and Workman, 1970; Volk and Haerendel, 1971; Goldman et al., 1976]. Several computer simulation studies based on the mechanism of the $\bar{E} \times \bar{B}$ gradient drift instability have done well in reproducing the late time plasma cloud evolution in the nonlinear regime [Scannapieco et a1., 1976; Doles et al., 1976]. No detailed data have previously been available on the electron density structure within the structured cloud to compare with these studies. The results reported here represent the first measurements of the electron density structure by the penetration of rocket probes through the striated cloud region.

\section{Electron Density Measurements}

The six electron density probe payloads were carried to apogee altitudes ranging from 200 to 250 km by Nike-Hydac rockets. The electron density was measured by a $6.4-\mathrm{cm}$ diameter probe protruding a length of one meter forward from the nose cone along the rocket spin axis. The combination $r f$ and $\mathrm{dc}$ probe gives both the desired high spatial resolution ( $\sim 1$ meter) of electron density variations, and good absolute accuracy of the density. The details of these electron density probes have been given [Baker, et al., 1978] and will not be described in further detail.

Detailed electron density results are presented here from rocket probes that penetrated striated barium clouds Fern and Esther. (The two probe rockets launched into event Diane penetrated the enhanced electron density region associated with the ion cloud, but did not show evidence of traversing striated structures, so are included here only in the summary Table 1.) 
TABLE 1. Summary of STRESS Probe Results

\begin{tabular}{|c|c|c|c|}
\hline Event & $\begin{array}{l}\text { Summary of } \\
\text { Electron Density } \\
\text { Cloud Traversal }\end{array}$ & $\left.10^{6} \mathrm{~cm}^{-3}\right)$ & $\begin{array}{l}\text { Altitude } \\
\text { of Peak } \\
(\mathrm{km})\end{array}$ \\
\hline $\begin{array}{l}\text { Diane } \\
\text { Diane }\end{array}$ & $\begin{array}{l}\text { Smooth layer }(\sim 10 \mathrm{~km}) \text {. } \\
\text { One sharp finger } \\
(\sim 1.5 \mathrm{~km}) \text { imbedded } \\
\text { in layer. }\end{array}$ & 1.4 & 162 \\
\hline $\begin{array}{l}\text { Es ther } \\
\text { Es ther }\end{array}$ & $\begin{array}{l}\text { Smooth layer ( } \sim 24 \mathrm{~km}) \text {. } \\
\text { Ten striation fingers } \\
\text { imbedded in layer. }\end{array}$ & $\begin{array}{l}0.7 \\
5.0\end{array}$ & $\begin{array}{l}177 \\
173\end{array}$ \\
\hline Fern & $\begin{array}{l}\text { Enhanced region over } \\
\text { large altitude range } \\
\text { (130-210 km), stri- } \\
\text { ations from } 170 \text { to } \\
210 \mathrm{~km} \text {. } \\
\text { Slight enhanced re- } \\
\text { glon over large al- } \\
\text { titude range (112- } \\
200 \mathrm{~km}) \text {. }\end{array}$ & 1.3 & 171 \\
\hline
\end{tabular}

Barium release Esther occurred at 2301:09 UT (1701:09 CST) on 13 March 1977 and the two probing rockets encountered the ion cloud 28 and 46 minutes after release. The profile for the first rocket, Figure 1(a), shows an enhanced electron density from approximately $160 \mathrm{~km}$ to $200 \mathrm{~km}$ (rocket ascent) compared with the background (descent) values. The profile is relatively smooth, showing no large scale structures as as evidence of cloud striations, but it is possible that striations had not as yet developed. (The sharp peaks evident in the E-region are sproadic E-layers not associated with this

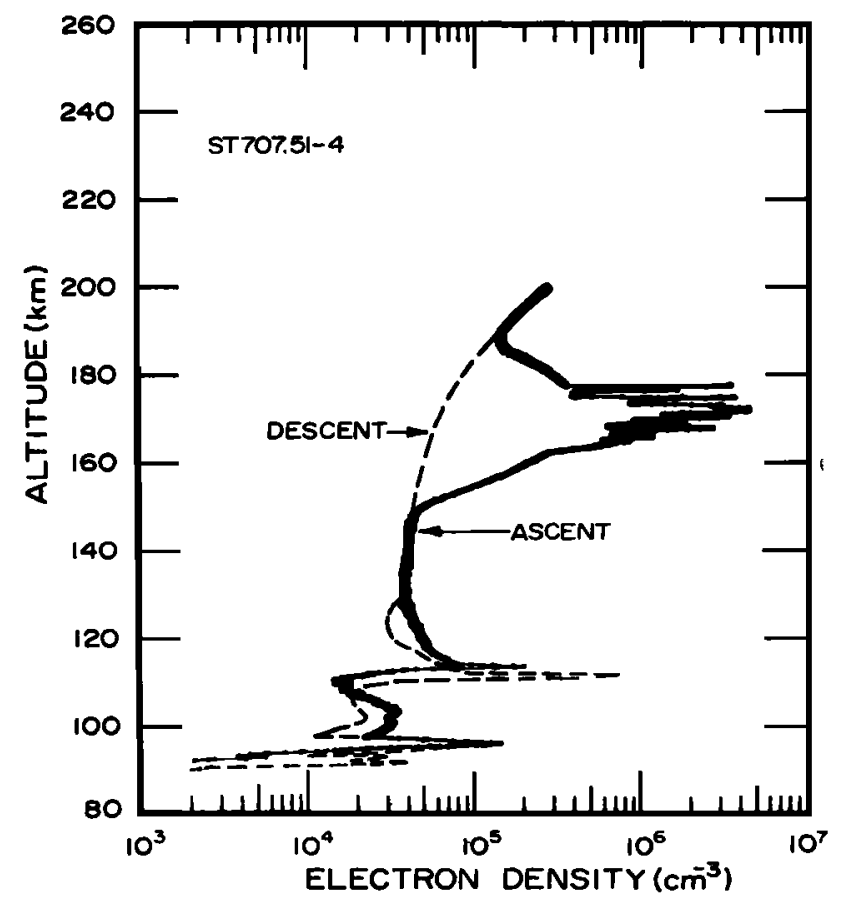

barium release.) The layer associated with the ion cloud has a peak electron density of $7 \times 10^{5}$ $\mathrm{cm}^{-3}$ at $177 \mathrm{~km}$ with a width (half amplitude) of $24 \mathrm{~km}$. At the peak of the layer, the density is enhanced over the ambient by nearly an order of magnitude.

The second probe rocket flown into the barium cloud Esther at release plus 46 minutes penetrated the fon cloud and produced an electron density profile, Figure 1(b), that showed large scale structures in the $163-178 \mathrm{~km}$ region imbedded in a genera1 layer similar to that probed by the earlier rocket. The peak value of electron density at $173 \mathrm{~km}$ of $5 \times 10^{6} \mathrm{~cm}^{-3}$ shows an enhancement of about two orders magnitude over the normal ionosphere.

The entry of the rocket probe into the striated cloud region is consistent with the cloud geometry as determined from electron density contours from ground-based radar returns [Gonzales, 1978]. (Note that due to the ambient light level, no optical images of cloud and striations were possible.) An expanded version of the electron density structure of the striated region (Figure $1(b))$ found by the probe rocket around $170 \mathrm{~km}$ is shown in the time plot of Figure 2. This plot shows the electron density from $T+140$ to $T+160 \mathrm{sec}$ of probe rocket flight time. This includes all of the striations penetrated by the probe in the altitude region between 163 and $178 \mathrm{~km}$. For discussion, the striation "fingers" have been numbered. The features have varying widths (half amplitude) from $0.17 \mathrm{sec}$ (feature 9) to $2.45 \mathrm{sec}$ on feature 7 . Note how some of the fingers, notably 3,6 , and 10 , have very fast fall times (about 20 milliseconds).

Relating the observed variations to spattal feature geometry is not simple since the observations represent a single path cut through the spatial structure. As a first attempt to relate

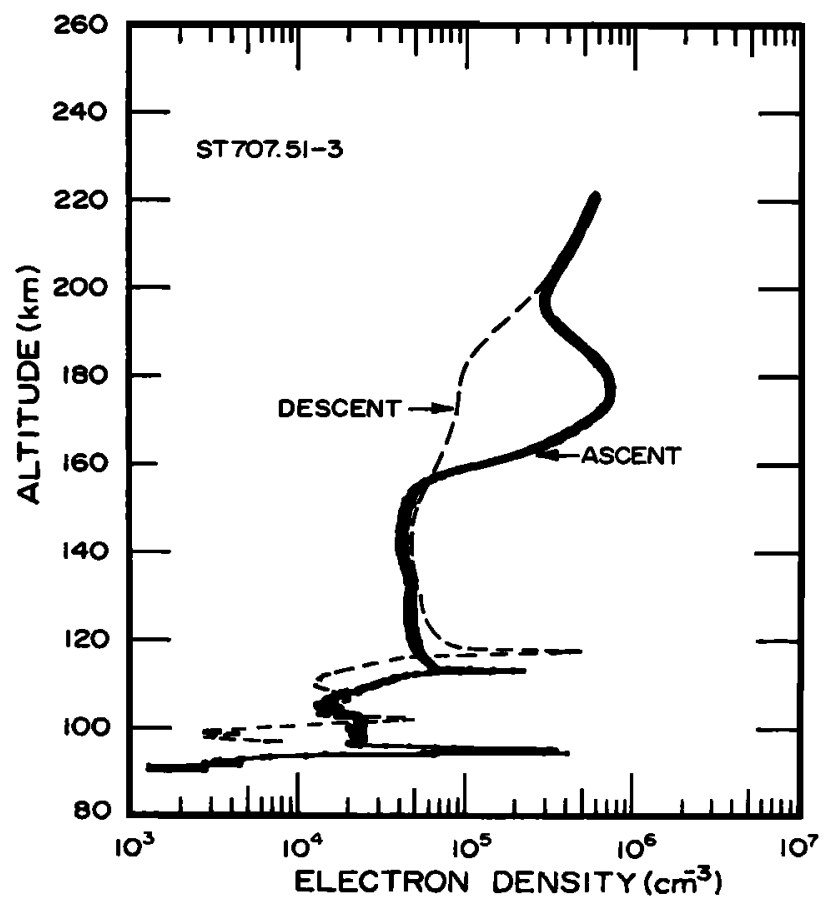

Fig. 1. Electron density profiles measured by rocket probes flown into event Esther: (a) 28 minutes after release, (b) 46 minutes after release. 


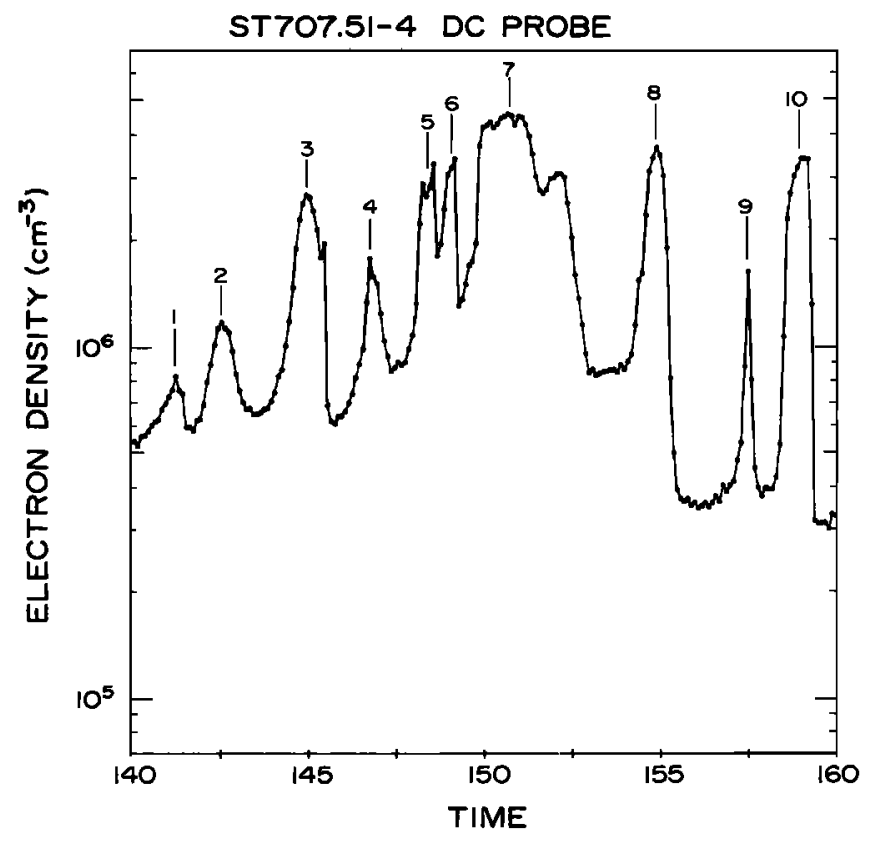

Fig. 2. Region of electron density striations measured from $\mathrm{T}+140$ to $\mathrm{T}+160$ seconds (163$178 \mathrm{~km}$ ) on probe flight into event Esther ( $R+46$ minutes). The density fingers are numbered to aid discussion.

the observations to spatial structure, the dimensions of the features across magnetic field lines were calculated by utilizing the component of the rocket velocity perpendicular to the terrestrial magnetic field $(800 \mathrm{~m} / \mathrm{sec})$. The total rocket velocity at this time was about $1310 \mathrm{~m} / \mathrm{sec}$ so all dimensions would be about a factor of 1.6 larger as measured by actual rocket probe cut through the structures along the flight path. The peak density measured (feature 7) of $4.7 \mathrm{x}$ $10^{6} \mathrm{~cm}^{-3}$ is a factor of 6 larger than the valley following it. The density falls after the last structure (feature 10) from a value of $3.5 \times 10^{6}$ $\mathrm{cm}^{-3}$ by over an order of magnitude in about $30 \mathrm{~m}$ travel normal to $B$. Other features such as 4 and 9 have rise times (a factor of $e$ ) of slightly more than a tenth of a second, which corresponds to a movement across the $B$ field of about 90 meters.

Release Fern occurred at 2246:09 UT on 14 March 1977 and the probe rocket penetrated the barium cloud at 42 minutes after release giving the electron density profile of Figure 3 . The probe entered the enhanced region due to the cloud at $130 \mathrm{~km}$ indicating the effects of the cloud extended well down into the E-region. The enhanced regton extended on the high side to over $200 \mathrm{~km}$. The main electron density layer showed a broad peak of $1.2 \times 10^{6} \mathrm{~cm}^{-3}$ at about $150 \mathrm{~km}$ and showed a relatively smooth profile up to about $170 \mathrm{~km}$ when structures appeared, giving evidence of passing through striated regions of the cloud. This region of striations persisted until the electron density returned to the normal F-region values at about $210 \mathrm{~km}$.

Comparison of the results from two probe flights into the striated region of barium clouds does not allow anygeneralizations about structure characteristics, especially since no optical coverage was available which would have established the rocket position within the regions. Nevertheless, the interesting differences between the structure characteristics from the two probed flights should be pointed out. Eirst, the striated region for Fern (Figure 3) was much broader in altitude (extending over $40 \mathrm{~km}$ ) than that for Esther, while Figure 3 shows the striated regions for Fern to be along a smooth profile continuing until the ambient background is measured. Final$1 y$, the details of the striated region for event Esther (Figure 2) shows ten distinct fingers with electron density variations as much as an order of magnitude, whereas for event Fern (Figure $3)$, the features are not as distinct with electron density variations of about a factor of two. It should be noted that the development of the finger-like structure in the density profiles is reminiscent of both optical pictures of barium cloud striations and predicted spatial development from the simulation studies of Scannapieco, et al., [1976], Doles, et al., [1976], and others.

The general results of measurements of electron density in the three distinct barium clouds is summarized in Table 1 .

\section{Spectral Features of Electron Density Variations}

The electron density variations found within the striated plasma clouds were analyzed by power spectral density analysis techniques using a fast Fourier transform. The square of the relative electron density fluctuations (irregularity power) is shown as a function of frequency (top scale) and wavenumber (lower scale) in Figure 4 for event Esther averaged from 140-153 $\mathrm{km}$, which includes most of the striation features. The rocket velocity component normal to the assumed direction of the features was used to

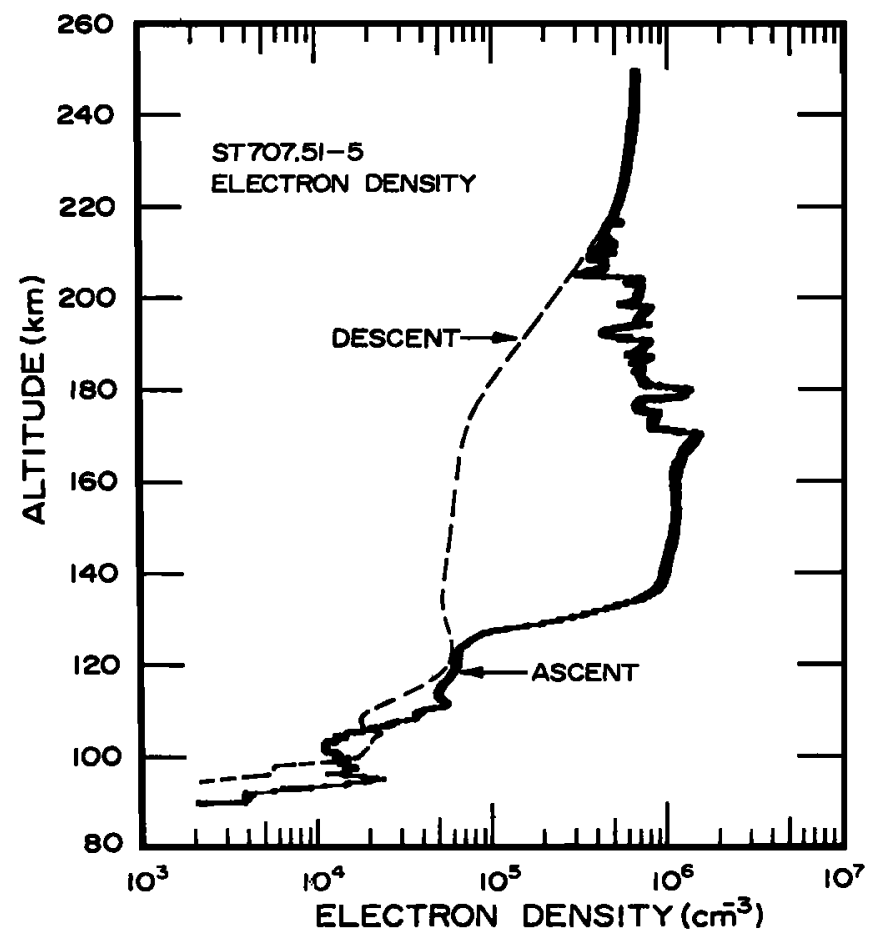

Fig. 3. Electron density profile from probe flight flown 42 minutes after release of event Fern. 
FREQUENCY $(\mathrm{Hz})$

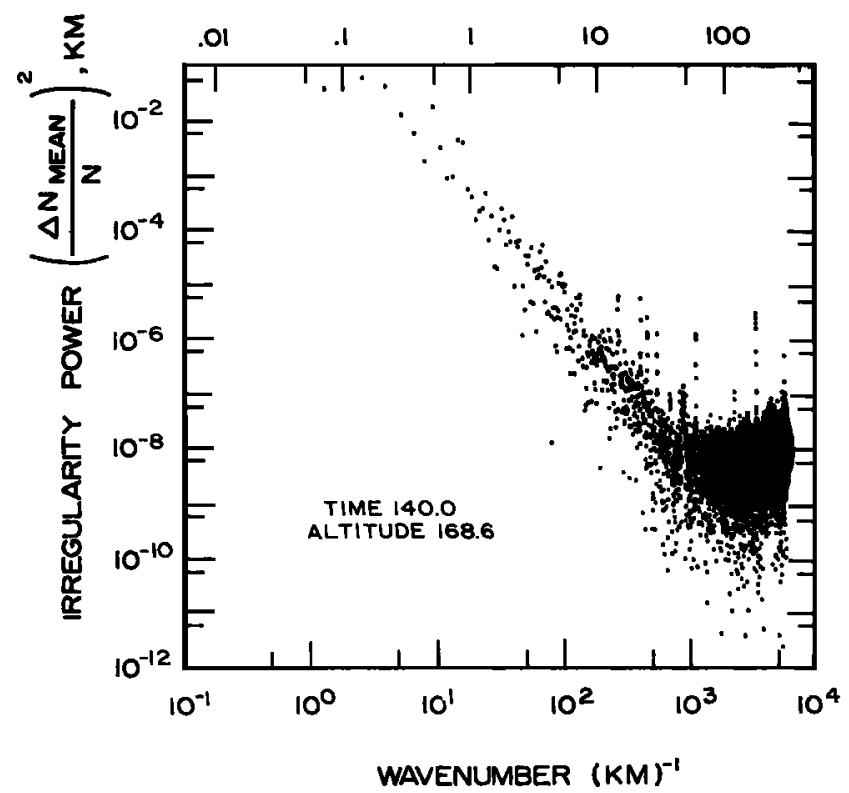

Fig. 4. Power spectral density of electron density irregulartites from rocket probe data shown in Figures 2(b) and 3 in the striated cloud region of event Esther.

relate the frequency spectrum to a wavenumber spectrum appropriate to a low phase velocity plasma wave. The spectral distribution between about 0.2 and $50 \mathrm{~Hz}\left(4-1000 \mathrm{~km}^{-1}\right)$ can be approximately represented by a power law distribution with a spectral index of about -2.5. This same analysis for the striation region of event Fern gives similar results. These results are in good agreement with those of the simulation studies by Scannapieco, et al. [1976] based on non1inear calculations of the $\overline{\bar{E}} \times \bar{B}$ instability mechanism.

Interpretation of the results reported orieily here is continuing and will be the subject of subsequent publications. The general development of the clouds deployed in the STRESS program and suggestions as to the geometry of the cloud and the probe rocket traversals are discussed by Linson and Baxter [1978]. These suggestions will be folded into future analys is in an attempt to better define the spatial relationships of the cloud phenomena and the measured electron density structure. Further interpretation of the electron density irregularity spectra and their implications to the plasma clouds and other ionospheric phenomena are presented in a paper in process [Kelley, et al., 1978].

Acknowledgements. It is a pleasure to acknowledge the efforts of the team that successfully carried out the difficult rocket measurements program under the direction of L. Car1 Howlett, Utah State University; Herb Mitche11, RD Associates; and Edward F. Allen, Space Data Corporation. The data reductions assistance of Dennis Delorey and associates at Boston College is also gratefully recognized. These measurements were sponsored by the Defense Nuclear Agency as part of the STRESS Program, with Majors Beverly Wayne Motal and Robert Bigoni serving as program managers.

\section{References}

Baker, K.D., J.C. U1wick, M.C. Kelley, L.C. Howlett, G.D. Allred, D. Delorey and N. Grossbard, Electron Density Structure in Barium Clouds-Measurements and Interpretation, Final Report, Contract No. DNA 001-76-C-0278, Utah State University, Logan, Utah, February 1978.

Davis, T.N. and D.D. Wallis, Observations of ionospheric motions using barium ion clouds from Space Research XII, ed. by S.A. Bowhill, L.D. Jaffe, M.J. Rycroft, vol. II, p, 935, Akademie-Verlag, Berlin, 1972.

Davis, T.N., G.J. Romick, E.M. Wescott, R.A. Jeffries, D.M. Kerr and H.M. Peek, Observations of the development of striations in large barium ion clouds, Planet, Space Science, $22(1): 67-78,1974$.

Doles, J.H. III, N.J. Zabusky and F.W. Perkins, Deformation and strlation of plasma clouds in the ionosphere, 3,: Numerical simulations of a multi-level model with recombination chemistry, J. Geophys. Res. 81(34):5987-6004, 1976.

Goldman, S.R., L. Baker, S.L. Ossakow, A.J. Scannapieco, Striation formation associated with barium clouds in an inhomogeneous ionosphere, J. Geophys. Res., 91(28):50975113, 1976.

Gonzalez, V., Radar Tracking and Measurements of the Ion Cloud, in Proceedings of the STRESS Final Data Review Meeting, ed. by Dan McDaniels, Stanford Research Institute, Menlo Park, California, in publication 1978.

Haerendel, G., R. Lust, and E. Rieger, Motion of artificial ion clouds in the upper atmosphere, Planet, Space Science, 15(1):1-18, 1967.

Haerendel, G. and R. Lust, Artificial plasma clouds in space, Sci. Amer., 219(81), 1968.

Haerendel, G. and R. Lust, Electric Fields in the Ionosphere and Magnetosphere, from Particles and Fields in the Magnetosphere, ed. by B.M. McCormac, p. 213, D. Reide1 Publishing Co., Dordrecht, 1970.

Kelley, M., K.D. Baker and J.C. Ulwick, Late time barium cloud striations and their possible relationship to equatorial spread-F, submitted to J. Geophys. Res., 1978.

Linson, L.M. and J.B. Workman, Formation of striations in ionospheric plasma clouds, J. Geophys. Res., 75(16): 3211, 1970.

Linson, L.M. and D.C. Baxter, Size, Shape and Age of Ion Clouds, in Proceedings of the STRESS Final Data Review Meeting, ed. by Dan McDaniels, Stanford Research Institute, Menlo Park, California, in publication 1978.

Rosenberg, Norman W., Observations of striation formation in a barlum ion cloud, J. Geophys. Res., 76(28): 6856, 1971.

Scannapieco, A.J., S.B. Ossakow, S.R. Goldman, and J.M. Pierre, Plasma cloud late time striations spectra, J. Geophys. Res., 81(34): 6037-6045, 1976 .

Volk, H.J. and G. Haerendel, Striations in Lonospheric ion clouds, 1., J. Geophys. Res., 76(19): 4541, 1971 .

(Received April 5, 1978; revised May 30, 1978; accepted June 13, 1978.) 